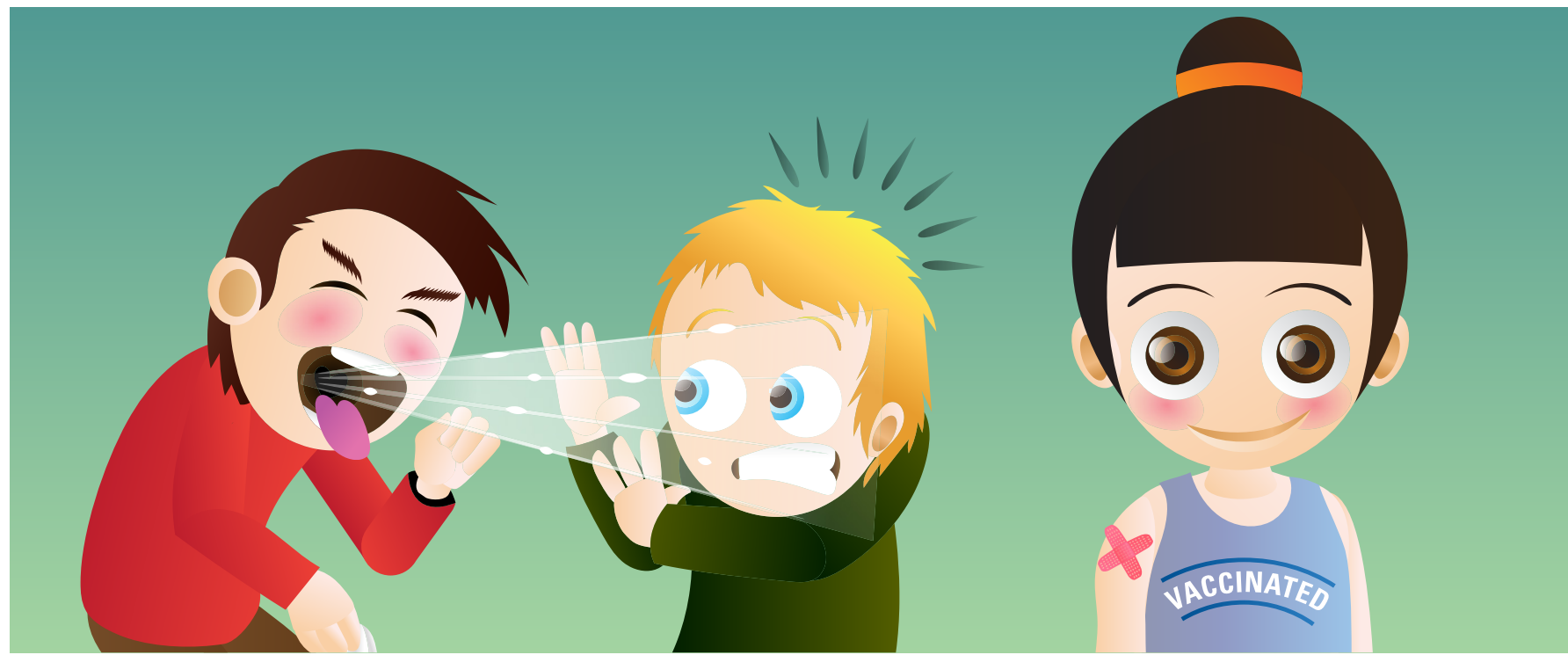

\title{
WHY IS IT IMPORTANT TO IMPROVE VACCINES AGAINST LATENT TUBERCULOSIS?
}

\section{Mario Alberto Flores-Valdez*}

Biotecnología Médica y Farmacéutica, Centro de Investigación y Asistencia en Tecnología y diseño del Estado de Jalisco (CIATEJ), Guadalajara, Mexico

REVIEWED BY:

AIDAN 12 YEARS OLD
Tuberculosis (TB) is a contagious disease spread by people who have the bacteria Mycobacterium tuberculosis within their lungs. These bacteria are expelled during coughing and can then infect others. TB is mainly present in developing countries, but because travel is so easy these days, a single infected person could potentially spread TB to people in several different places. TB can become a fatal disease, especially in children, so vaccination is recommended shortly after birth in countries that have a lot of infected people. Today, the only available vaccine does not work against the latent form of infection. During latent TB, M. tuberculosis remains "dormant" or hiding, within an infected person without causing trouble, but upon weakening of the immune (defense) system, it "wakes up" and causes disease, including coughing and the potential to spread to other people. In this article, I present ideas to improve vaccines to prevent latent $T B$, as a way to decrease the chances of starting new infectious cycles upon "awakening" of the dormant bacteria. 


\section{VACCINE}

A mixture made of one or more microbes (viruses or bacteria) or parts of these organisms that aims to stimulate our body's defenses, in order to help the body to eliminate the microbe or reduce the damage caused by any illness the microbe causes [1], for example, uncontrolled coughing, weight loss, paralysis, and very high fever, among others.

\section{MICROBES}

Tiny, microscopic organisms (in the range of one millionth of a meter, or even smaller than this) that can only be seen using tools called microscopes. Some microbes can cause disease to people, animals or plants, and others can be used to produce yogurt, cheese, bread, or wine, among other foods.

\section{BCG}

Bacille of CalmetteGuérin, an attenuated from Mycobacterium bovis that does not cause disease to healthy people.

\section{ATTENUATED}

A microbe that is normally capable of causing disease, which has been weakened in the lab so that it is no longer harmful, yet can be used by the immune system to promote the rise of defenses.

\section{INTRODUCTION}

What is a vaccine? In the simplest terms possible, a vaccine is a mixture made of one or more microbes (viruses or bacteria) or parts of these organisms that aims to stimulate our body's defenses, in order to help the body to eliminate the microbe or reduce the damage caused by any illness the microbe causes [1], for example, uncontrolled coughing, weight loss, paralysis, and very high fever, among others.

The goal of a vaccine is to prevent disease, and one of the greatest challenges in creating a vaccine is to stimulate the body enough to allow our defenses against that organism to arise while not causing any unpleasant side effects such as swelling and pain. Usually, scientists perform experiments to determine how well a potential vaccine can protect against an infection, as well as to figure out how safe the vaccine is. Vaccines work differently in different people, due to factors in the environment (for example, other infectious microbes that the person may be exposed to, or the quality and amount of food that person eats) as well as basic differences in the way peoples' defense systems work. These differences make it a good idea to test vaccines in different groups of people in what are called clinical studies. It is also important to keep in mind that some vaccines might not work in different countries because the microbes there might be slightly different than the microbes used to develop the vaccine.

\section{WHY IS IT NECESSARY TO FIND A BETTER VACCINE AGAINST TUBERCULOSIS?}

Tuberculosis (TB) is a very important public health problem. It is estimated that in 2014, 9.6 million people developed TB, and almost 2 million people died of this disease, where India, Indonesia, and China presented almost half of the cases occurring in the world [2]. TB is caused by a bacteria called Mycobacterium tuberculosis that is spread from person to person through the air, when someone with the disease coughs, talks, or sneezes. It is estimated that one third of the people infected with this bacteria do not get sick but still have the bacteria hiding in their bodies, in what doctors call a "latent" (or dormant) state.

There is only one vaccine currently approved for TB in humans, and it is called Mycobacterium bovis Bacillus Calmette-Guérin (BCG). This vaccine has been given to more than 3 billion people since it was developed in 1921, with around 115 million doses per year given to newborns. The BCG vaccine is made from living bacteria that have been weakened in the lab so that they are unable to cause disease. This type of vaccine, using weak but still living bacteria, is called a live attenuated vaccine. 


\section{LATENT \\ INFECTION}

A condition where a microbe remain within a person or animal (or even plants) without causing any visible damage to them.

\section{GENE}

Part of the hereditary material present in every living cell and that helps the cell to work at its full capacity when used or needed.

Live attenuated vaccines, such as BCG, usually work very well to prevent infections with the real, disease-causing organism. Unfortunately the BCG live vaccine is not good at protecting people against every one of the different types of TB that exist in nature - it protects against some types but not others. Also, in people with latent TB, the BCG vaccine does not fully prevent the dormant bacteria from "waking up" and causing disease. So, if we really want to protect everyone against TB, we know that a stronger, better vaccine is necessary.

\section{VACCINE CANDIDATES AGAINST LATENT TUBERCULOSIS}

In the last 5 years or so, scientists have been trying to create a vaccine that will keep people with latent TB infection from getting sick. The strategies and reasons why scientists think these new vaccine candidates will be better than current BCG, are described in Table 1. One of these possible new vaccines is made from a mixture of two substances that are found in mice with TB: one substance is produced by the TB bacteria when the mice are actually sick with $\mathrm{TB}$ and the other is produced by the bacteria during chronic infection. So far, this vaccine has been tested in both mice and a kind of monkey called a macaque. In both mice and monkeys, the vaccine seems to help prevent animals with latent infections from getting sick [3]. Other types of vaccines are being tested in animals too, although so far none of them look very promising.

My research group has also been working hard to develop a better vaccine against TB. We took the same BCG bacteria that is used in the current vaccine and modified it in the lab by deleting one of its genes. Genes are the "instructions" inside a cell that help it to live and grow and perform its functions. We found that eliminating one specific gene made the bacteria easier for the body to see and therefore easier for the immune system

\section{TABLE 1 | STRATEGIES FOR DEVELOPING NEW VACCINES AGAINST TUBERCULOSIS.}

\section{What is the strategy?}

Remove genes from harmful Mycobacterium tuberculosis

Add genes from disease-causing

Mycobacterium tuberculosis, to the safe, attenuated BCG bacteria

Mix bacterial substances known to be produced in the body during infection with tuberculosis

Modify or change the BCG bacteria so that it looks more like the natural forms of TB that people actually get infected with

\section{Why is it expected to work?}

It decreases the ability of the harmful bacteria to cause disease

It makes the "safe-to-use" bacteria look more like the bacteria that causes disease, which activates the immune system better

It stimulates the immune system and helps the body to defend itself against several forms of the harmful bacteria

It increases the chance that the immune system will recognize the harmful bacteria when it sees it 


\section{FIGURE 1}

Schematic representation of latent tuberculosis infection and vaccine development.

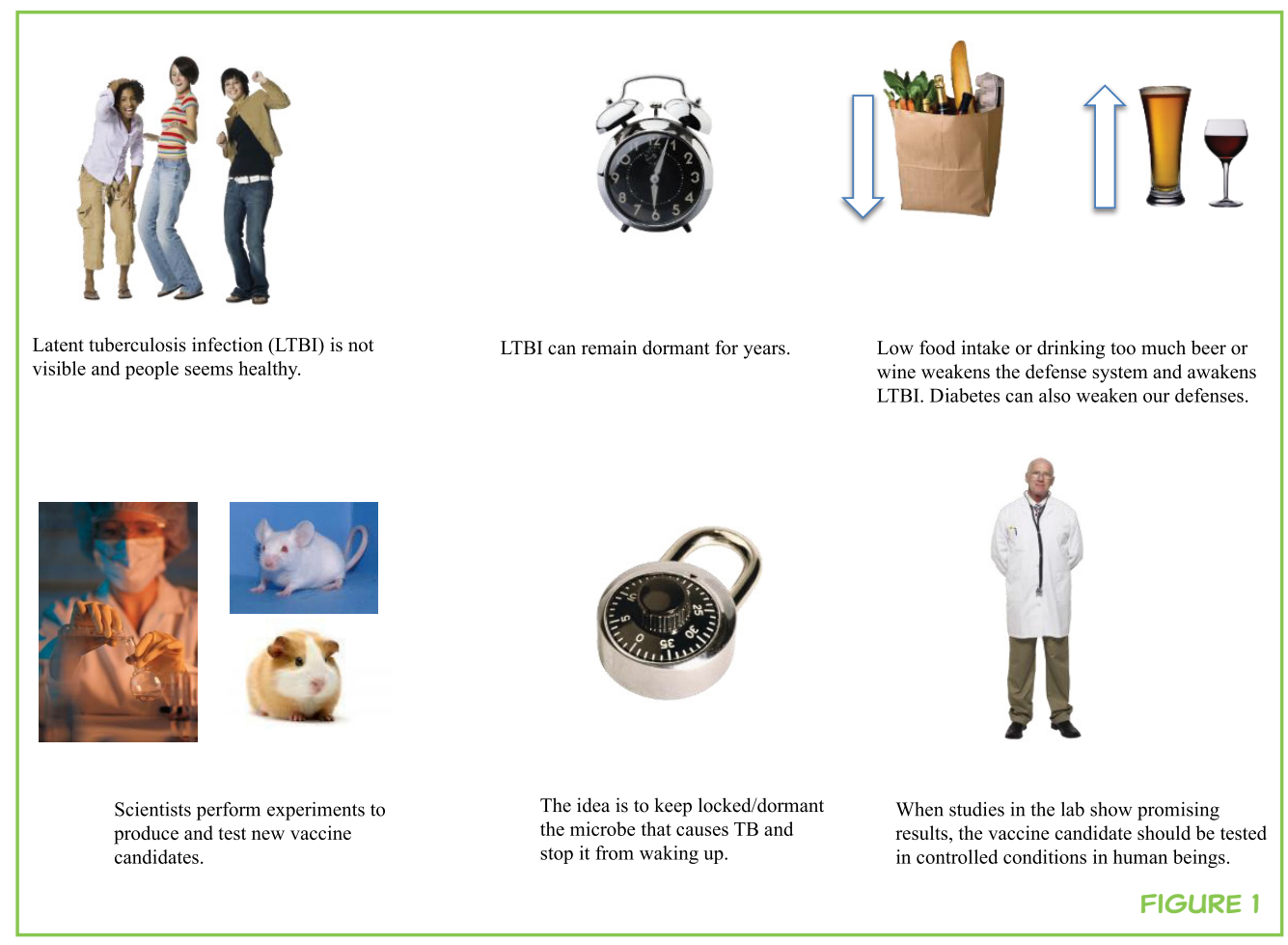

to fight off. We also discovered that, at least in mice, this modified BCG vaccine helps to prevent dormant bacteria from waking up and causing disease. That means that our new vaccine might be better than the vaccine available today!

We just got approval for our results being published in a scientific journal, and we are also planning further experiments to make sure this vaccine really does help to control latent TB. We hope that we have created a vaccine that will finally work to protect people against all the different types of TB. We also hope that this vaccine will be safe and useful in people with other diseases, such as HIV. HIV-infected people are more likely to get sick from TB because their immune systems are weak. Maybe a new vaccine will eventually be able to slow or stop the spread of TB in the world. Figure 1 shows basic aspects of latent TB infection and vaccine development.

\section{ACKNOWLEDGMENTS}

I am indebted to my son, Xavier A. Flores-Barba, for being my inspiration for this work, as well as for his help in creating Figure 1. The National Council of Science and Technology (CONACYT, project \# 86396) in Mexico provided financial support for starting my quest for new vaccine candidates against tuberculosis. I am grateful with Dr. Rogelio Hernández-Pando and César Pedroza-Roldán, colleagues who were and are still very supporting in pursing these ideas along with me. 


\section{REFERENCES}

1. Available at: http://www.cdc.gov/vaccines/vac-gen/imz-basics.htm

2. Available at: http://www.who.int/tb/publications/global_report/gtbr15_main_text.pdf

3. Lin, P. L., Dietrich, J., Tan, E., Abalos, R. M., Burgos, J., Bigbee, C., et al. 2012. The multistage vaccine $\mathrm{H} 56$ boosts the effects of $\mathrm{BCG}$ to protect cynomolgus macaques against active tuberculosis and reactivation of latent Mycobacterium tuberculosis infection. J. Clin. Invest. 122:303-14. doi:10.1172/JCl46252

SUBMITTED: 02 May 2016; ACCEPTED: 02 September 2016; PUBLISHED ONLINE: 20 September 2016.

EDITED BY: Fulvio D’Acquisto, Queen Mary University of London, UK

CITATION: Flores-Valdez M (2016) Why is Still Important to Improve Vaccines against Tuberculosis? Front. Young Minds 4:19. doi:10.3389/frym.2016.00019

CONFLICT OF INTEREST STATEMENT: The author declares that the research was conducted in the absence of any commercial or financial relationships that could be construed as a potential conflict of interest.

COPYRIGHT () 2016 Flores-Valdez. This is an open-access article distributed under the terms of the Creative Commons Attribution License (CC BY). The use, distribution and reproduction in other forums is permitted, provided the original author(s) or licensor are credited and that the original publication in this journal is cited, in accordance with accepted academic practice. No use, distribution or reproduction is permitted which does not comply with these terms.

\section{REVIEWED BY}

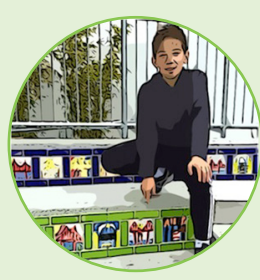

\section{AIDAN, 12 YEARS OLD}

$\mathrm{Hi}$, I am Aidan, and I live in San Francisco. I enjoy all types of life and physical science, sports, and taking care of toddlers. At school, I like science, history, and Chinese. I have gone to 16 countries on 6 cruises where I have learned a lot about their history, art, and science. I right now enjoy fencing most of my weekday afternoons.

\section{AUTHOR}

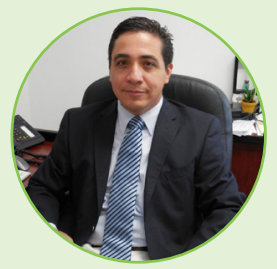

\section{MARIO ALBERTO FLORES-VALDEZ}

I am a Microbiologist and Molecular Biologist, and I am deeply interested in understanding how a tiny cell (Mycobacterium tuberculosis) is able to interact with our defense system and remain viable for long time without causing evident signs of overt disease, and I try to generate means (vaccines) to stop it from further causing trouble to human beings. *floresv@ciatej.mx, floresvz91@gmail.com 